ERRATUM

\title{
Atherogenic lipoprotein phenotype and low-density lipoprotein size and subclasses in patients with growth hormone deficiency before and after short-term replacement therapy
}

Manfredi Rizzo, Roman Trepp ${ }^{1}$, Kaspar Berneis ${ }^{2}$ and Emanuel R Christ ${ }^{1}$

Deparment of Clinical Medicine and Emerging Diseases, University of Palermo, Palermo, Italy, ${ }^{1}$ Division of Endocrinology and Diabetes, University Hospital of Bern, Inselspital, 3010 Bern, Switzerland and ${ }^{2}$ Medical University Hospital, Bruderholz and Clinic for Endocrinology, Diabetes and Clinical Nutrition, University Hospital of Zurich, Zurich, Switzerland.

(Correspondence should be addressed to E R Christ; Email: emanuel.christ@insel.ch)

The authors and journal apologize for an error in the above paper which appeared in 156 (3) 361-367. The acknowledgements should appear as below.

\section{Acknowledgements}

The study was funded by grant from the Swiss National Foundation to Emanuel R. Christ (No. \#32000B0-100146). Kaspar Berneis was supported by a grant from Swiss National Foundation (3200BO-105258). The authors gratefully acknowledge the excellent technical assistance of S. Vosmeer.

European Journal of Endocrinology 159355 